\title{
Chapter 9 \\ Social Polarization and Socioeconomic Segregation in Shanghai, China: Evidence from 2000 and 2010 Censuses
}

\author{
Zhuolin Pan, Ye Liu, Yang Xiao, and Zhigang Li
}

\begin{abstract}
China's rapid economic growth since the early 1980s has been accompanied by a substantial increase in economic inequality. Economic restructuring, rural-urban migration, globalization and marketization have jointly led to a transformation of the socio-spatial structure of large Chinese cities. Although a handful of studies have examined the level and pattern of socioeconomic segregation in a particular Chinese city using neighbourhood-level census data from the year 2000, little research has been done to investigate in-depth changes in the level and pattern of segregation using more up to date and more geographically detailed data. This chapter aims to examine the levels, patterns and drivers of socioeconomic segregation in Shanghai, China, using neighbourhood-level and subdistrict-level data from the 2000 and 2010 decennial population census. This chapter uses the dissimilarity index to measure the overall level of socioeconomic segregation by occupation and household registration (hukou) status. Based on a location quotient and neighbourhood composition, it also illustrates the change in the spatial pattern of segregation. The chapter ends with a discussion on the possible drivers of segregation and policy suggestions to combat segregation in large Chinese cities.
\end{abstract}

Keywords Socioeconomic segregation - Occupation - Hukou status - Shanghai • China

Z. Pan · Y. Liu (凶)

School of Geography and Planning, Sun Yat-Sen University, Guangzhou, China

e-mail: liuye25@mail.sysu.edu.cn

Z. Pan

e-mail: panzhl6@mail2.sysu.edu.cn

Y. Xiao

Department of Urban Planning, Tongji University, Shanghai, China

e-mail: yxiao@tongji.edu.cn

Z. Li

School of Urban Design, Wuhan University, Wuhan, China

e-mail: zhigangli@whu.edu.cn 


\subsection{Introduction}

Over the past four decades, rapid economic growth has been interwoven with internal and international migration during a process of globalization, which has led to an unprecedented socioeconomic transition around the world (Marcińczak 2012). Rapid growth in the economy is inevitably accompanied by a substantial increase in socioeconomic inequality (Marcińczak et al. 2015), and China is no exception. According to the National Bureau of Statistics of China, the Gini Index of the country increased from 0.317 in 1978 to 0.465 in 2016, which indicates a widening income gap. In the largest Chinese cities, such as Beijing, Shanghai and Guangzhou, rising income inequality has resulted in socioeconomic segregation. Evidence from the 2000 and 2010 censuses showed that many large cities in China have experienced a rise in residential segregation by class, household registration (hukou) status and housing tenure ( $\mathrm{Li}$ and $\mathrm{Wu}$ 2006, 2008; Chen and Li 2014). The increase in residential segregation has resulted in a number of detrimental consequences, such as the reproduction of marginality, the prolonged and rising rate of unemployment in deteriorated towns, the widening of social inequality and the weakening of social solidarity (Wilson 1987; Bolt et al. 2010). Understanding the pattern and drivers of residential segregation in large cities in China will help policymakers to achieve the goal of building an inclusive and harmonious society.

A growing body of literature has explored patterns of residential segregation in large Chinese cities since the beginning of the reforms in 1978. Earlier studies have focused mainly on the delineation of socio-spatial differentiation in Chinese cities (Gu and Kesteloot 1997). More recently, growing attention has been paid to the drivers and mechanism of residential segregation ( $\mathrm{Gu}$ et al. 2006; Li and Wu 2006). Nevertheless, most earlier studies on residential segregation were based on the fourth and fifth waves of the national population census carried out in the years 1990 and 2000, respectively (Gu and Kesteloot 1997; Feng and Zhou 2003). Recently, a few studies have examined the residential segregation of a particular city, such as Shanghai and Nanjing, using data from the sixth round of population census conducted in 2010 (Wu et al. 2014, 2018; Shen and Xiao 2020), but surprisingly, little attention has been paid to neighbourhood segregation with regard to hukou status, occupation and socioeconomic status (Liao and Wong 2015; Wu et al. 2018). Moreover, little research has been done to investigate the changes in the spatial pattern of residential segregation over time in globalized Chinese cities, and the process of urban socio-spatial reconfiguration remains under-researched.

This chapter aims to examine and compare the level and pattern of socioeconomic segregation between 2000 and 2010 by occupation and hukou status in Shanghai using neighbourhood-level and subdistrict-level data from the decennial population census. As a polarizing global city with a dramatically rising number of both superrich and extremely disadvantaged and poor citizens, Shanghai provides an ideal laboratory to investigate the patterns, drivers and consequences of residential segregation against the backdrop of globalization and marketization in China. 


\subsection{Residential Segregation in Large Cities in China}

Residential segregation has always existed in the history of urbanization (Nightngale 2012). In Europe and North America, racial segregation is regarded as the most persistent form of segregation, and a large number of empirical studies have been devoted to this form of segregation (Massey 1985; Wilson 1987). Although some globalizing Chinese cities attract a large number of international migrants, they account for only a very small proportion of the total population of these cities (for example, $0.71 \%$ of Shanghai's total population in 2000), exerting an insignificant effect on the spatial pattern of residential segregation. Socioeconomic status has become a major dimension of residential segregation in the new millennium in the transition from a planned economy to a market-oriented economy ( $\mathrm{Li}$ and $\mathrm{Wu} 2008$ ). Socioeconomic segregation was not severe in the period of the planned economy when the state exerted a monopoly over a wide range of resources, and state-owned work units played an important role in arranging resource allocation ( $\mathrm{Wu}$ and $\mathrm{Li} 2005)$. The work unit determined workers' wage levels and the allocation of means of subsistence, such as housing and health care. Meanwhile, the hukou system imposed stringent constraints on internal migration and excluded outsiders from urban public services (Chan 2009). Chinese cities experienced a low degree of socioeconomic differentiation before the early 1980 s as a result of the state-dominated housing system and the stringent hukou system.

The advent of the reform and the opening up has provided more freedom and incentives for the growth of the private sector and thereby generated a new-rich class, but the reform of the state-owned work units has also led to millions of workers being made redundant, and housing is now no longer allocated by work units (Wu 2004; $\mathrm{Li}$ and $\mathrm{Wu} 2008$ ). Although the government still owns the land after the housing reform, real estate developers can obtain the land use right through the land conveyance system. Supported by bank loans, real estate developers have gradually become the principal participants in the housing development ( $\mathrm{Fu} 2013$ ). Housing reform has promoted the formation of housing marketization in China and increased levels of housing consumption. From 1984 to 2010, the rate of homeownership increased from 9.4 to $89.3 \%$ in China. However, the market mechanism has led to the rise of house prices in large cities, and housing has become a commodity which can be purchased on the market rather than a welfare benefit allocated by the state and work units (Wu and Li 2005; Logan et al. 2010). The market-oriented housing reform has aggravated the segregation among socioeconomic status groups, thus restructuring the socio-spatial structure of Chinese cities (Walder and He 2014; Song et al. 2017). In addition, internal migration has also contributed to the socio-spatial restructuring of urban China (Liao and Wong 2015). The loosening of the hukou system and the growth of low-end urban job opportunities have caused the influx of migrants into urban areas since the mid-1980s (Fan 2008). However, the long-established dual system between migrants and urban residents excludes migrants from the mainstream social welfare system (Chan and Zhang 1999; Chan and Buckingham 2008). Migrants suffer from only limited accessibility to the urban formal housing system, and they 
are unlikely to be able to afford the soaring cost of housing in large Chinese cities (Huang and Jiang 2009; Logan et al. 2009). Therefore, they have no choice but to concentrate in particular urban areas and form migrant enclaves, such as Little Hubei in Guangzhou and Zhejiangcun in Beijing (Zhang 2001; Liu et al. 2015). In contrast, higher socioeconomic status groups prefer to live in gated communities with guaranteed safety and favourable amenities (Wu and Webber 2004). Thus, the rising housing stratification exacerbates the residential segregation in large cities in China.

Numerous studies on residential segregation have been conducted since the late 1980s, when socio-spatial differentiation began to emerge in urban China (Xu et al. 1989; Gu and Kesteloot 1997). The reform amplified some of the effects inherited from the pre-reform era and aggravated the residential segregation during the transitional period (Wu et al. 2010). Meanwhile, market forces became interwoven with state forces to generate multiple dimensions of segregation, including segregation by hukou status, education, housing tenure, working status and occupation ( $\mathrm{Wu}$ and $\mathrm{Li}$ 2005; $\mathrm{Li}$ and $\mathrm{Wu} 2008$ ). It can be expected that with increasing levels of marketization of housing, the widening of the income gap by occupation, the influx of migrants, and the level of socioeconomic segregation in Shanghai will increase (Shen and Xiao 2020).

\subsection{Data and Methods}

\subsubsection{Data}

In this chapter, we examine the level and the pattern of socioeconomic segregation at the neighbourhood (residential committee, juwei) level and the subdistrict (jiedao) level in Shanghai using data from the 2000 and 2010 decennial population censuses. The residential committee along with the village committee is the lowest level of administration unit in China with an average population of 3,000. The subdistrict is the second lowest level of administration unit in urban areas and is constituted by several residential committees. We are not able to examine socioeconomic segregation by occupation at the neighbourhood level in 2000 due to a lack of relevant data. The research area of the current study covers the entire administrative area of Shanghai, including 329 subdistricts and 6,256 residential committees for the 2000 census database, and 230 subdistricts and 5,432 residential committees for the 2010 census database. Please note that administration units' boundaries in Shanghai changed slightly over the decade.

Although income is not recorded in Chinese population censuses, it is highly related to occupation and hukou status, both of which are available in census data. Occupation has been largely affected by market factors following the economic reform and represents the best single-variable indicator of socioeconomic status. We divided occupations into three categories: the TOP group, the MIDDLE group and the 
BOTTOM group. The TOP group consists of heads of government agencies (HEA), party agencies, enterprises, institutional organizations and professional personnel (PRO); the MIDDLE group consists of clerks and related personnel (CLE); and the BOTTOM group consists of employees in commerce and service sectors (COM), people operating manufacturing and transportation equipment and related personnel (MAN) and employees in the farming, forestry, animal husbandry and fishery sectors (FAR). In contrast, hukou status is affected by institutional factors and underlies a deep rural-urban chasm in China (Chan 2009). Rural hukou holders in cities normally have limited access to the public goods and services provided by the city government (Wu 2002). As for residential segregation by hukou, people living in Shanghai are divided into two groups: Shanghai hukou holders and migrants. In this chapter, the term 'migrants' refers to people who have lived in Shanghai for at least 6 months (whose place of usual residence is Shanghai) without Shanghai hukou (non-Shanghai hukou holders), and 'locals' refers to people who have lived in Shanghai for at least 6 months and who have Shanghai hukou.

During the period 2000-2010, the total population of Shanghai increased from 16.74 million to 23.02 million. The influx of migrants from other parts of China contributed to the growth of the population of Shanghai. Migrants accounted for $23 \%$ of the total population in 2000, and the proportion increased to $39 \%$ in 2010 . Regarding occupational groups, the proportion of the TOP group and MIDDLE group increased slightly, while the proportion of the BOTTOM group dropped from 72 to $66 \%$ over the decade (Fig. 9.1). With the improvement in educational attainment or technical ability of migrants, the proportion of the TOP group has increased along with the influx of migrants since 2000. As shown in Fig. 9.2, the central area and

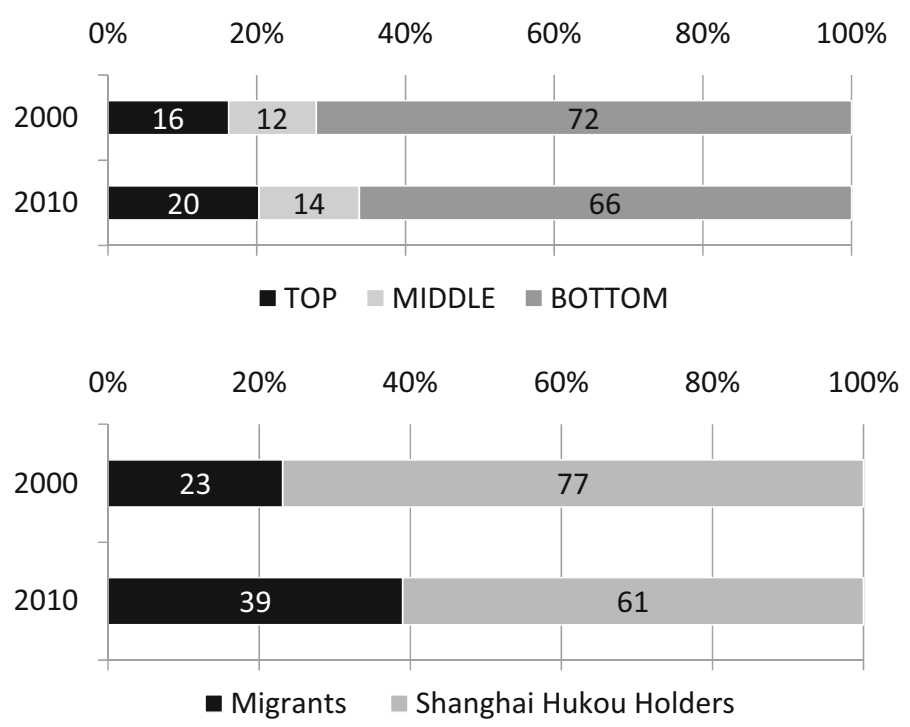

Fig. 9.1 Distribution of occupational groups and hukou status in 2000 and 2010 


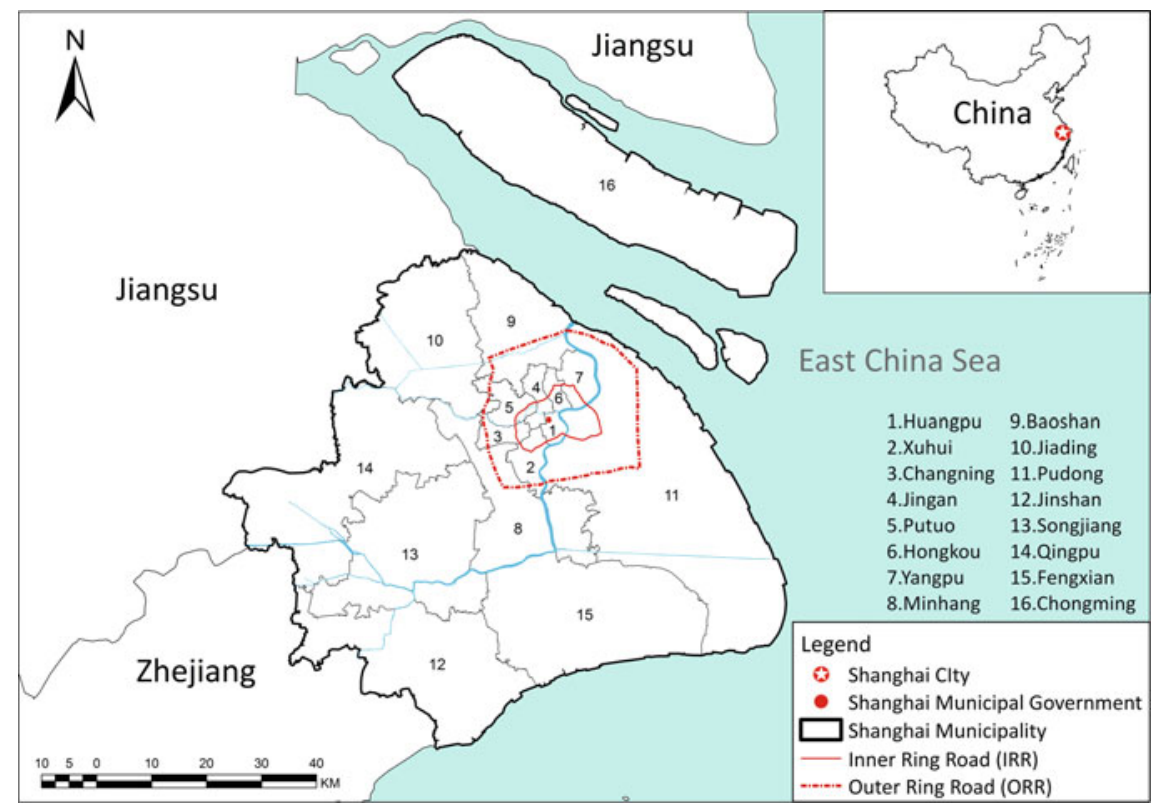

Fig. 9.2 Geography of Shanghai

the suburban area are demarcated by the Outer Ring Road (hereafter ORR), and the west bank of the Huangpu River (Puxi) inside the Inner Ring Road (hereafter IRR) is the old town of Shanghai, where the Shanghai municipal government and traditional cultural, residential and commercial centres are located. The east bank of the Huangpu River (Pudong) inside the IRR is the financial centre of Shanghai, and it accommodates many advanced producer service firms and the headquarters of multinational and national corporations. Pudong has experienced radical changes in its economic and demographic landscapes and built environment over the past three decades. Besides, as the northernmost district of Shanghai, Chongming is proceeding with its development in the ecological environment and industry in recent years, and a large proportion of the territories are still undeveloped or under protection.

\subsubsection{Methods}

We examined residential segregation in Shanghai using several methods. In the first stage, we used the traditional index of dissimilarity (DI) to assess the overall level of socioeconomic segregation in 2000 and 2010 for Shanghai. Indices of dissimilarity for occupational groups and hukou status were calculated at both the neighbourhood level and the subdistrict level. In the second stage, we adopted several approaches to depict the spatial pattern of socioeconomic segregation of Shanghai in 2000 and 2010 
by occupational groups. First, we visualized the distribution of the location quotient (LQ) of the TOP group and BOTTOM group. Second, we applied the typology of units (subdistricts and neighbourhoods) for further analysis. Third, we inspected the location of the TOP group of Shanghai and revealed the changes in the social-spatial pattern over the period 2000-2010. In the third stage, we illustrated the spatial pattern of segregation by hukou status and then discussed its connection to segregation by occupation.

\subsection{Results}

\subsubsection{Level of Segregation in Shanghai}

Tables 9.1 and 9.2 report the results of DI by occupation. Regarding major occupational groups, there was a moderate level of segregation between the TOP and the BOTTOM group (0.32), and a moderate level of segregation between the MIDDLE and the BOTTOM group (0.35) at the subdistrict level in 2000. From 2000 to 2010, the level of segregation at the subdistrict level did not change dramatically, and there was only a moderate level of segregation between the TOP and the BOTTOM group (0.33) in 2010. Regarding sub-major occupational groups, DI for all pairs of occupational groups except DI for segregation between FAR and any other occupational group was below 0.5 at the subdistrict level, which indicated that FAR were segregated from any other occupational groups. Besides, Tables 9.1 and 9.2 suggest that the level of segregation at the neighbourhood level was higher than that at the

Table 9.1 Dissimilarity Indices (multiplied by 100) by occupation for Shanghai in 2000 and 2010 at subdistrict level (left) and in 2010 at neighbourhood level (right)

\begin{tabular}{|c|c|c|c|c|c|c|c|c|c|c|c|c|c|c|c|}
\hline & HEA & PRO & CLE & $\mathrm{COM}$ & MAN & FAR & & & & HEA & PRO & CLE & COM & 1 MAN & FAR \\
\hline \multirow{6}{*}{ 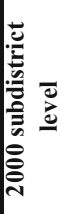 } & & 22 & 27 & 27 & 48 & 75 & \multirow{6}{*}{ 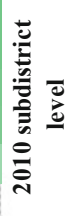 } & HEA & \multirow{6}{*}{ 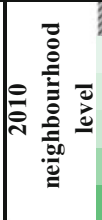 } & & & & & & \\
\hline & 25 & 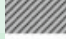 & 14 & 20 & 46 & 75 & & PRO & & 33 & & & & & \\
\hline & 31 & 11 & IIII & 14 & 41 & 72 & & CLE & & 39 & 22 & & & & \\
\hline & 25 & 17 & 16 & & 34 & 70 & & COM & & 44 & 33 & 26 & & & \\
\hline & 34 & 35 & 36 & 26 & & 55 & & MAN & & 62 & 60 & 52 & 41 & & \\
\hline & 73 & 79 & 81 & 74 & 58 & & & FAR & & 86 & 86 & 83 & 79 & 66 & \\
\hline
\end{tabular}

Table 9.2 Dissimilarity Indices (multiplied by 100) between Top, Middle and Bottom groups for Shanghai in 2000 and 2010

\begin{tabular}{|lccc|}
\hline & TOP - MID & TOP - BOT & MID - BOT \\
\hline $\mathbf{2 0 0 0}$ subdistrict level & 14 & 32 & 35 \\
$\mathbf{2 0 1 0}$ subdistrict level & 16 & 33 & 28 \\
$\begin{array}{l}\mathbf{2 0 1 0} \text { neighbourhood } \\
\text { level }\end{array}$ & 24 & 47 & 38 \\
\hline
\end{tabular}


subdistrict level in 2010. At the neighbourhood level, there was a higher level of segregation between the TOP and the BOTTOM group (0.47), and FAR as well as MAN were highly segregated with other occupational groups, especially HEA and PRO. In 2000 and 2010, FAR accounted for $11.3 \%$ and $6.3 \%$, respectively, which led to a relatively higher level of segregation between FAR and other occupational groups.

Regarding hukou status, DI between migrants and Shanghai hukou holders increased over the period 2000-2010. The hukou-based segregation at the subdistrict level increased from 0.24 to 0.30 . DI at the neighbourhood level also increased from 0.31 to 0.39 . This indicates a moderate level of segregation by hukou status.

In summary, Shanghai is characterized by a moderate level of segregation by occupation and hukou status over the period 2000-2010, and the level of segregation between the TOP group and the BOTTOM group and that between migrants and local hukou holders increased over the same period. Moreover, the level of segregation by occupational groups exceeded the level of hukou-based segregation both at the subdistrict level and neighbourhood level in 2000 and 2010.

\subsubsection{Spatial Pattern of Occupation-Based Segregation in Shanghai}

The spatial distribution of the TOP group changed substantially from 2000 to 2010 (see Fig. 9.3). In 2000, people from the TOP group were mainly concentrated in the Puxi area and in areas between the Inner Ring Road (IRR) and the Outer Ring Road (ORR) in the southwest corner (where many research institutions, universities, government organizations and a sub-CBD were located). Outside the ORR, the suburban area had only a few sporadic subdistricts with a higher concentration of the TOP group. In 2010, the spatial distribution of the TOP group showed a characteristic of sprawling from the IRR to the ORR, and the old town of Shanghai (small area next to the west bank of the river) was largely occupied by the BOTTOM group. A significantly increased concentration of the TOP group was found in the Pudong area. Since the development of the Pudong area started in 1990, the area has gradually become the financial centre of China. Most of the residents from the TOP group concentrated here are from private sector organizations, such as transnational corporations. In 2010, the TOP group was more concentrated at the neighbourhood level than at the subdistrict level and was located mainly along with the IRR of Shanghai. Besides, a few sporadic neighbourhoods showed a higher level of concentration of the TOP group in the suburban area, in which some high-tech parks are located.

There is a stark contrast between the residential distribution of the BOTTOM group and that of the TOP group. In 2000, a higher level of concentration of the BOTTOM group was found in the Pudong area and the suburban area. Most of these areas were farmland or industrial parks. From 2000 to 2010, with the expansion of urban land, some of the farmland or industrial parks were expropriated by the 


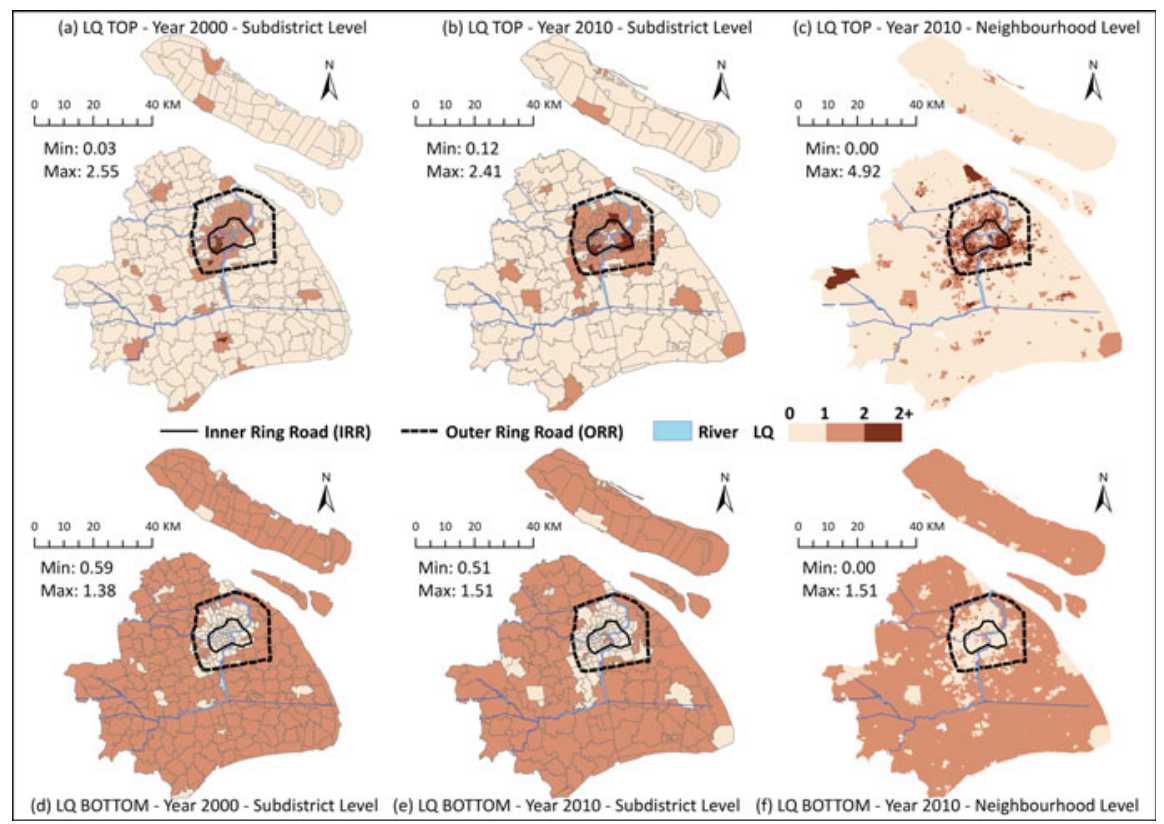

Fig. 9.3 Location quotient for the TOP and BOTTOM occupational groups in 2000 and 2010

government, such as the Pudong area. Some residents of the BOTTOM group were concentrated in the old town of Shanghai in 2010. However, although they have the most convenient location in Shanghai, they suffer from shabby and crowded residential conditions compared with other locations.

As we can see from Fig. 9.4, the geography of subdistricts' socioeconomic intermixing experienced dramatic changes from 2000 to 2010. In 2000, the low socioeconomic status subdistricts outnumbered the middle and high socioeconomic status subdistricts. Especially in the suburban area, nearly all subdistricts belonged to low socioeconomic status subdistricts. Inside the IRR, the old town of Shanghai was characterized by residents with middle socioeconomic status, while the west of the old town was characterized by residents with high or middle socioeconomic status. The Pudong area witnessed a growing number of mixed subdistricts where residents with high, middle and low socioeconomic status lived together. However, in 2010, although the low socioeconomic status subdistricts remained dominant across Shanghai, their share had decreased significantly, and the proportion of the middle to high socioeconomic status subdistricts had increased by $18 \%$ over the decade. These subdistricts were mostly distributed on both sides of the IRR, surrounding the old town of Shanghai. In 2010, the old town of Shanghai was characterized by residents with low or middle socioeconomic status. The outskirts of the central area were largely identified as mixed, middle to high and high socioeconomic status neighbourhoods, whereas in the suburban area, most of the neighbourhoods were identified as low socioeconomic status neighbourhoods. From 2000 to 2010, with 


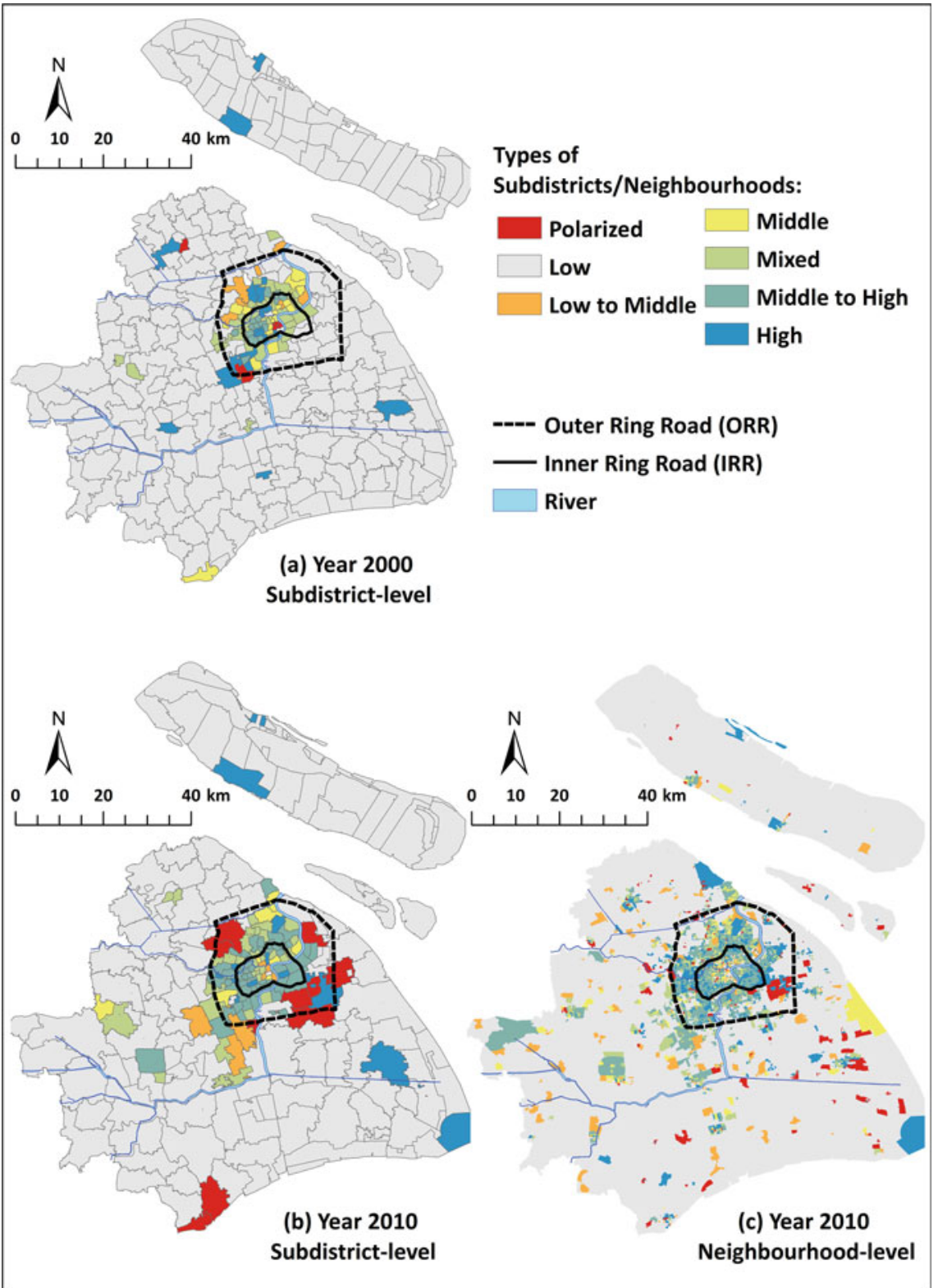

Fig. 9.4 Classification of subdistricts/neighbourhoods by socioeconomic composition in 2000 and 2010 
the expansion of urban land and the improvement in the average socioeconomic status of the population in Shanghai, the districts with residents with high socioeconomic status sprawled from the west of the old town to other areas inside the ORR. The pattern at the neighbourhood level was much more fragmentized due to smaller scale geographic units. Neighbourhoods in the old town largely belonged to low, low to middle or middle socioeconomic status neighbourhoods, surrounded by middle to high and high socioeconomic status neighbourhoods.

Figure 9.5 depicts the residential landscape of the TOP group in Shanghai. In 2000, subdistricts of Q1 were mainly located in and dispersed across the central area and largely situated near the universities, government organizations and the sub-CBDs. In 2010, Q1 was situated mainly between the area of the ORR and the IRR, and especially concentrated in the Pudong area, which has become the financial centre of Shanghai, attracting an increasing number of experts from all over the world. Although the proportion of each type of subdistrict remained fairly stable over the period 2000-2010, the spatial distribution changed significantly.

\subsubsection{Spatial Pattern of Hukou-Based Segregation in Shanghai}

In 2000, most Shanghai hukou holders lived in the old town of Shanghai, and migrants were mainly concentrated along both sides of the ORR. In 2010, the location quotient of migrants was found at a low level inside the IRR. Migrants' agglomerations had been moved away from the IRR, and neighbourhoods on both sides of the IRR were mainly inhabited by local hukou holders in 2010 (Fig. 9.6).

Above all, it was found that segregation by occupation is interwoven with segregation by hukou status. Over the period 2000-2010, the spatial distribution of the BOTTOM group was similar to that of migrants, while the spatial distribution of the TOP group was contrary to that of migrants. This indicates that, in Shanghai, most migrants occupy the lowest position in the socioeconomic hierarchy. Shanghai local hukou is highly associated with higher socioeconomic status, while those without Shanghai hukou may suffer from lower socioeconomic status and so be segregated from residents with high socioeconomic status.

\subsection{Drivers of Changing Patterns of Residential Segregation in Shanghai}

Our findings reveal that the level of segregation by occupational groups has surpassed the level of hukou-based segregation, and occupation has become an increasingly significant factor in the reconstruction of the social space. In the post-reform era, educational attainment, occupation and income are interrelated and reinforce each 


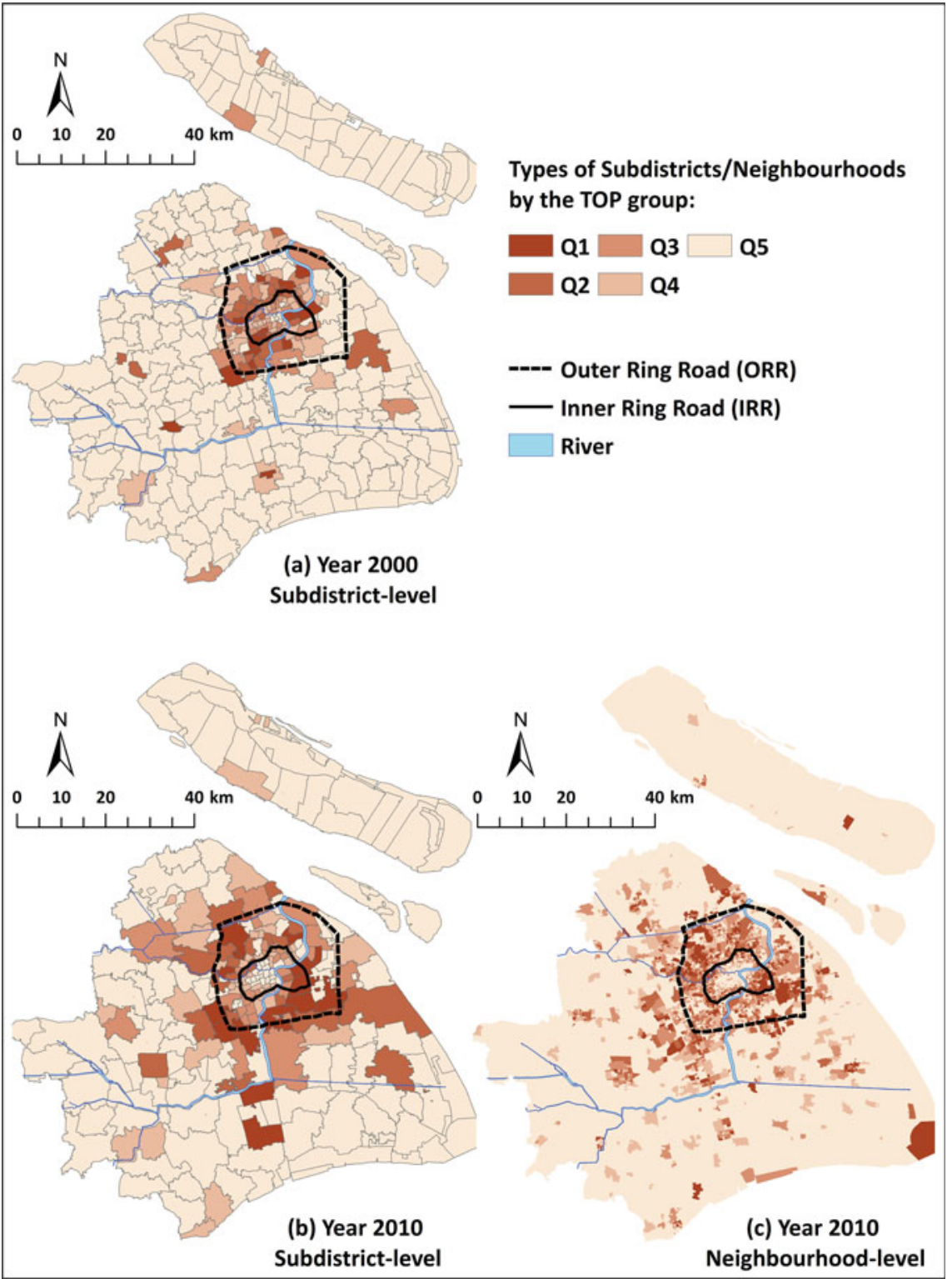

Fig. 9.5 Location of the TOP occupational group in 2000 and 2010 


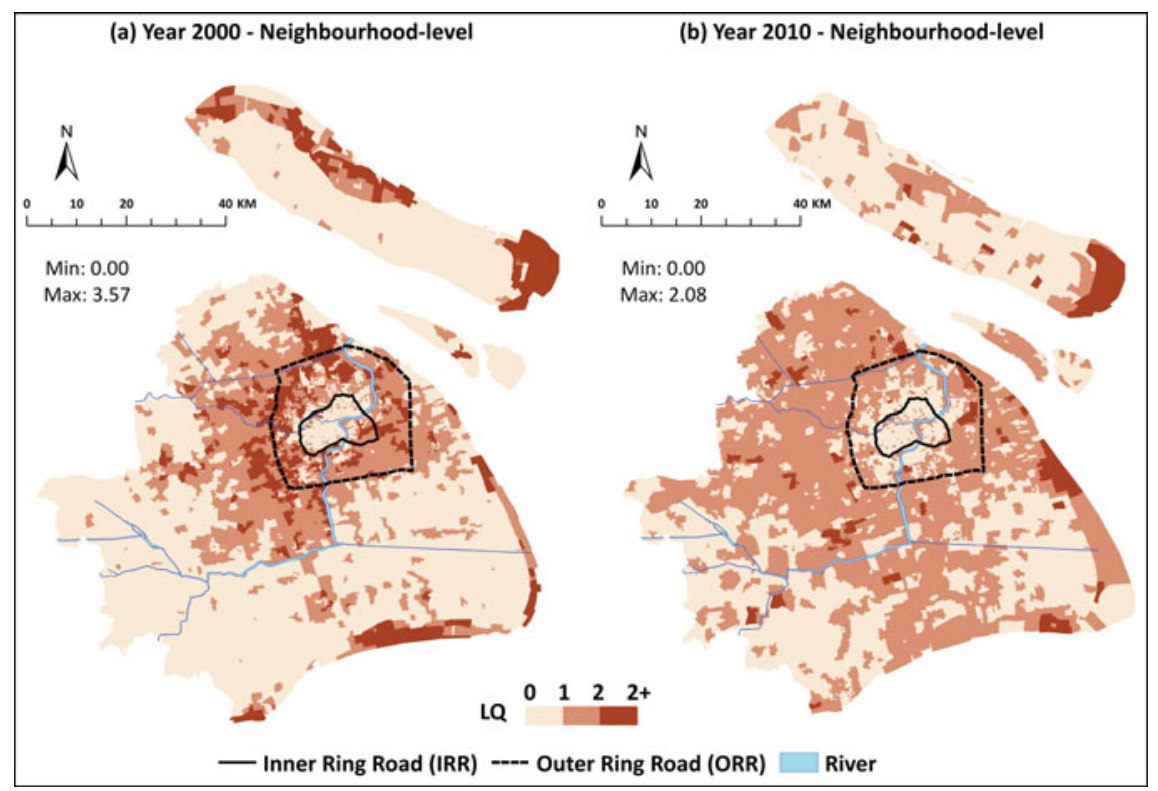

Fig. 9.6 Location quotient of migrants in 2000 and 2010

other. The rapid growth of the TOP group and the huge proportion of the BOTTOM group in the occupational hierarchy may exacerbate income inequality and socioeconomic segregation in Chinese rapidly globalizing cities. The proportion of the TOP group increased over the 2000-2010 decade, and the BOTTOM group still accounted for a large share of the population in 2010. Under the influence of globalization and marketization, housing accessibility is increasingly dependent on occupation and income (Bian and Liu 2005; Wu et al. 2018). As a result, the spatial process of socioeconomic polarization accelerates and results in residential segregation (Xiao et al. 2016). In the era of financialization of housing, the appreciation of housing values and the rapid increase of house prices have driven the process of socio-spatial differentiation, sorting people with different abilities to pay into different areas (Song et al. 2017; Shen and Xiao 2020). Under such circumstances, housing differentiation is supposed to be intensified, and market forces are assumed to play an increasingly dominant role in shaping the process of segregation of Shanghai over time.

Nevertheless, the institutional factors can never be ignored. In large Chinese cities, it is difficult for migrants without higher educational attainment to achieve upward social mobility (Wang and Fan 2012). The hukou system excludes migrants from a large variety of goods and services provided by local governments, thereby circumscribing unwanted migrants and maximizing government revenue (Zhang 2010; Chan 2012). In Shanghai, although migrants can apply for the urban hukou, they are obliged to meet several criteria, such as the possession of bachelor's degrees and regular residence in Shanghai or stable employment in formal enterprises. The qualified applicants will be ranked by the rating scheme and those applicants with a total 
score higher than the qualification mark set by the Shanghai government can attain urban hukou. These criteria are intentionally skewed in favour of those with higher educational attainment or technical credentials (Zhang 2010; Zhang and Wang 2010). Even though the hukou system has been relaxed and migrants can attain urban hukou easily in small- and medium-sized cities, in large cities, hukou remains as an insurmountable barrier for most of the migrants to obtain public goods and services such as education and medical insurance, owing to the high threshold and limited quota of urban hukou attainment in large Chinese cities. Nevertheless, as the Lewis turning point is reached, surplus rural labour has been absorbed by the manufacturing sector and labour supply has become limited in urban China. The labour-intensive growth model in China has gradually lost its competitiveness (Cai 2010; Zhang et al. 2011). Therefore, the reform will be deepened, and an increasing number of migrants will be encouraged to integrate into urban China to spur economic growth. The market mechanism will play a significant role in mobility and resource allocation, and the level of hukou-based segregation will decrease at the expense of the increasing level of segregation by socioeconomic status.

Additionally, social factors play an important role in shaping the process of segregation in large Chinese cities. Chain migration is one of the most important forms of migration, and migrants tend to congregate in a particular location with the aid of kinship ties and native place ties (Liu et al. 2015). These social ties are vital for migrant communities to survive and thrive in large cities, as newly arrived migrants tend to seek jobs and accommodation with the aid of their family, relatives and fellow townsmen (lao xiang) (Liu et al. 2012; Huang et al. 2017). Besides, poor socioeconomic status and lower educational attainment reinforce the disadvantaged position of migrants in urban China, who suffer from persistent discrimination by the local residents (e.g. exclusion from community activities, difficulty in constructing a social network with local residents) (Chen and Wang 2015). As a result, migrants are isolated by the local residents, and they subsequently prefer to congregate in migrant enclaves for both instrumental and emotional support (Liu et al. 2012). Both the internal cement within each migrant group and the external discrimination against migrant groups contribute to the residential segregation between migrants and local hukou holders in Chinese cities.

Besides, the historical legacy of urban inequality laid a foundation for the structure of urban space (Wu and $\mathrm{Li} 2005$; $\mathrm{Li}$ and $\mathrm{Wu} 2006$ ). In the pre-reform era, rural labourers were forced to stay in rural areas, and urban residents who were affiliated with state-owned work units lived in city centres (Wu 2002; Chan 2009). The process of the marketization of housing affected the acquisition of housing property rights (Wu 2017). In the early period after the reform in 1988, as the sitting tenants of public housing in Shanghai, local hukou holders could afford housing and acquire property at highly subsidized prices (Logan et al. 2009). They benefitted from the housing reform and thus owned housing properties at the centre of Shanghai. The offspring of the beneficiaries of the housing reform inherited these properties, and some of them still lived in the centre of Shanghai. Thus, the housing reform and the commodification of housing have led to the problem of housing unaffordability and housing inequality, and therefore familial financial support and intergenerational transmission of housing 
are increasingly important for young people to achieve homeownership (Cui et al. 2019). The drastic increase in house prices after the housing reform in Shanghai and the intergenerational transmission of housing reinforce the historical pattern of urban social space and aggravate the hukou-based segregation in Shanghai.

Moreover, urban planning by the local government also plays an active role in reshaping the socio-spatial configuration in Shanghai (Feng and Zhou 2003). The renewal projects in the rundown neighbourhoods have improved the living conditions and residential environment of the old town in Shanghai, attracting residents with a higher socioeconomic status and resulting in the gentrification of the city centre (He 2010). Besides, the development of the metro network and the construction of the new high-tech development zone have promoted the development of suburban areas and new towns. With the improvement of public transportation, residents who were employed in high-tech industries located in suburban areas tended to move to the periphery of the central area for a better job-housing balance and better living conditions (Liu and Hou 2014). Thus, Shanghai experienced the processes of gentrification and suburbanization (Yang 2005). Additionally, the construction of the metro network exerts a direct effect on house prices. Houses around the metro stations are more expensive than those away from metro stations, which are unaffordable for people from the BOTTOM group, aggravating segregation between the TOP and the BOTTOM groups. Through planning intervention, the Shanghai municipal government also contributed to the exacerbation of residential segregation.

Apart from the driving forces mentioned above, demographic factors, such as the family structure and household life cycle, play an important role in shaping the socio-spatial configuration in urban China (Feng and Zhou 2008). For example, the elderly may prefer inner-city areas with good access to public services, such as public-funded hospitals, over suburban areas, while families with children would rather live in gated communities in the periphery for more a spacious environment and better living conditions (Feng and Zhong 2018). The demographic processes result in socio-spatial differentiation in housing demands and thus shape the spatial pattern of residential segregation.

\subsection{Conclusion and Discussion}

China's economic reform has brought about a widening gap between the rich and the poor and thereby has led to a rise in socioeconomic segregation in large cities. This chapter provides an overview of the change in the level and spatial pattern of residential segregation in Shanghai over the period 2000-2010. Our findings reveal that socioeconomic status based on occupation has become a dominant axis of segregation in large Chinese cities, as the level of segregation by occupation has surpassed the level of hukou-based segregation. The evolving socioeconomic residential segregation patterns in Shanghai have emerged from the combination of market and institutional forces both of which favour higher socioeconomic groups over lower socioeconomic groups. 
An increasing level of segregation in Shanghai is affected by various driving forces at the macro, meso and micro levels. Market factors (e.g. globalization and marketization), institutional factors (e.g. the hukou system), social factors (e.g. social bonds within migrant groups and discrimination from the mainstream society), the historical legacy of urban inequality, urban planning practices and demographic processes (e.g. family structure and household life cycle) have been interwoven to reshape the sociospatial structure of Shanghai. The confluence of these forces has led to the change in the level and pattern of residential segregation. Inconsistent with findings from cities of transitional Central and Eastern European countries, where increasing economic inequality has promoted the formation of mixed neighbourhoods rather than segregated neighbourhoods (Marcińczak et al. 2015), our findings from Shanghai suggest that the widening of the income gap and the influx of internal migrants from elsewhere have led to an increasing level of socioeconomic segregation.

It would be difficult to reverse the trend of increased segregation in Chinese cities in the near future, as the market mechanism plays a dominant role in shaping the urban landscape (Xiao et al. 2016). However, it is advisable for Chinese policymakers to adopt the following measures to counter segregation. Most importantly, the government is advised to lower the threshold of attaining urban citizenship (urban hukou) and gradually remove institutional barriers against migrants. Current qualifications of urban hukou in large Chinese cities strongly favour those with higher educational attainment or desirable skills (Zhang 2010). In addition, strict rules and limited quotas exclude most of the migrants from urban hukou and the affiliated public goods and services such as pension and medical insurance. A comprehensive urban citizenship can improve migrants' integration and lower the level of residential segregation. Second, the government is advised to provide education and skill training for the low-end labourers and migrants since the accumulation of human capital is effective for migrants to integrate into the host society and achieve upward social mobility (Bian and Logan 1996).

Additionally, there is a need to provide more affordable housing in locations accessible to the disadvantaged. Recent years have witnessed large-scale redevelopment schemes carried out in many large cities. These redevelopment schemes are criticized because they fail to satisfy migrants' basic demand for accommodation and do not address the negative consequences of poverty concentration (Wu et al. 2012). Besides, policymakers are advised to promote the development of mixed communities by providing public rental housing ${ }^{1}$ in middle-class neighbourhoods or providing a rental allowance to avoid an excessive concentration of the vulnerable. Moreover, the disadvantaged are forced to congregate in enclaves with poor living environments. Providing open green spaces and improving the traffic conditions can increase the value of these areas and therefore attract residents with a higher socioeconomic status. Last but not least, the pursuit of land revenue by the local government

\footnotetext{
${ }^{1}$ Public rental housing is a government sponsored economic assistance aimed towards alleviating housing expenses for low-income families or individuals, retired elderly, disabled or migrants with stable employment in urban areas. The public rental housing is owned by the local government, and the rental price is slightly lower than the market rental price.
} 
has led to a rapid increase in the price of housing and increased resident segregation in urban China. Therefore, the local government should implement stiffer regulations on real estate investment. By implementing these strategies, governments can prevent the marginalization of the disadvantaged and ease the level of segregation in Chinese large cities.

\section{References}

Bian Y, Liu Y (2005) Social Stratification, home ownership, and quality of living: evidence from China's fifth census. Sociol Stud 82-98:243

Bian Y, Logan JR (1996) Market transition and the persistence of power: the changing stratification system in urban China. Am Sociol Rev 61(5):739-758

Bolt G, Özüekren AS, Phillips D (2010) Linking integration and residential segregation. J Ethn \& Migr Stud 36(2):169-186

Cai F (2010) Demographic transition, demographic dividend, and Lewis turning point in China. China Econ J 3(2):107-119

Chan KW (2009) The Chinese hukou system at 50. Eurasian Geogr Econ 50(2):197-221

Chan KW (2012) Migration and development in China: trends, geography and current issues. Migr Dev 1(2):187-205

Chan KW, Buckingham W (2008) Is China abolishing the hukou system? China Q 195:582-606

Chan KW, Zhang L (1999) The hukou system and rural-urban migration in China: processes and changes. China Q 160:818-855

Chen H, Li Z (2014) Tenure-based housing segregation under rapid urbanization in post-reform urban China: a case study of Guangzhou. Acta Geogr Sin 69(12):1821-1832

Chen Y, Wang J (2015) Social integration of new-generation migrants in Shanghai China. Habitat Int 49:419-425

Cui C, Deng W, Lu T (2019) Pathways to homeownership in urban China: transitions and generational fractures. J Housing Built Environ. https://doi.org/10.1007/s10901-019-09664-0

Fan C (2008) China on the move: migration, the state, and the household. New York, Routledge, London

Feng J, Zhong Y (2018) Restructuring of social space in Beijing from 2000 to 2010. Acta Geogr Sin 73(4):711-737

Feng J, Zhou Y (2003) The social spatial structure of Beijing metropolitan area and its evolution: 1982-2000. Geogr Res 22(4):465-483

Feng J, Zhou Y (2008) Restructuring of socio-spatial differentiation in Beijing in the transition period. Acta Geogr Sin 63(8):829-844

Fu Q (2013) Local state marketism: an institutional analysis of China's urban housing and land market. Chin Sociol Rev 46(1):3-24

Gu C, Chan R, Liu J et al (2006) Beijing's socio-spatial restructuring: immigration and social transformation in the epoch of national economic reformation. Prog Plan 66(4):249-310

Gu C, Kesteloot C (1997) Social polarisation and segregation phenomenon in Beijing. Acta Geogr Sin 52(5):384-393

He SJ (2010) New-build gentrification in central Shanghai: demographic changes and socioeconomic implications. Popul Space Place 16(5):345-361

Huang X, Dijst M, Van Weesep J (2017) Social networks of rural-urban migrants after residential relocation: evidence from Yangzhou, a medium-sized Chinese city. Hous Stud 32(6):816-840

Huang YQ, Jiang LW (2009) Housing inequality in transitional Beijing. Int J Urban Reg Res 33(4):936-956

Li ZG, Wu FL (2006) Socioeconomic transformations in Shanghai (1990-2000): policy impacts in global-national-local contexts. Cities 23(4):250-268 
Li ZG, Wu FL (2008) Tenure-based residential segregation in post-reform Chinese cities: a case study of Shanghai. Trans Inst Br Geogr 33(3):404-419

Liao B, Wong DW (2015) Changing urban residential patterns of Chinese migrants: Shanghai, 2000-2010. Urban Geogr 36(1):109-126

Liu W, Hou C (2014) Urban residents' home-work space and commuting behavior in Guangzhou. Sci Geogr Sin 34(3):272-279

Liu Y, Li Z, Breitung W (2012) The social networks of new-generation migrants in China's urbanized villages: a case study of Guangzhou. Habitat Int 36(1):192-200

Liu Y, Li Z, Liu Y et al (2015) Growth of rural migrant enclaves in Guangzhou, China: agency, everyday practice and social mobility. Urban Stud 52(16):3086-3105

Logan JR, Bian Y, Bian F (2010) Housing inequality in urban China in the 1990s. Int J Urban Reg Res 23(1):7-25

Logan JR, Fang Y, Zhang Z (2009) Access to housing in urban China. Int J Urban Reg Res 33(4):914935

Marcińczak S (2012) The evolution of spatial patterns of residential segregation in central European cities: the Łódź functional urban region from mature socialism to mature post-socialism. Cities 29(5):300-309

Marcińczak S, Tammaru T, Novák J et al (2015) Patterns of socioeconomic segregation in the capital cities of fast-track reforming postsocialist countries. Ann Assoc Am Geogr 105(1):183-202

Massey DS (1985) Ethnic residential segregation: a theoretical synthesis and empirical review. Sociol Soc Res 69:315-350

Nightngale CH (2012) Segregation: a global history of divided city. University of Chicago Press, Chicago

Shen J, Xiao Y (2020) Emerging divided cities in China: socioeconomic segregation in Shanghai, 2000-2010. Urban Stud 57(6):1338-1356

Song W, Mao N, Chen P et al (2017) Coupling mechanism and spatial-temporal pattern of residential differentiation from the perspective of housing prices: a case study of Nanjing. Acta Geogr Sin 72(4):589-602

Walder AG, He X (2014) Public housing into private assets: wealth creation in urban China. Soc Sci Res 46(3):85-99

Wang WW, Fan CC (2012) Migrant workers' integration in urban China: experiences in employment, social adaptation, and self-identity. Eurasian Geogr Econ 53(6):731-749

Wilson WJ (1987) The truly disadvantaged: the inner city, the underclass, and public policy. University of Chicago Press, Chicago

Wu F (2004) Urban poverty and marginalization under market transition: the case of Chinese cities. Int J Urban Reg Res 28(2):401-423

Wu F, He S, Webster C (2010) Path dependency and the neighbourhood effect: urban poverty in impoverished neighbourhoods in Chinese cities. Environ Plan A 42(1):134-152

Wu F, Zhang F, Webster C (2012) Informality and the development and demolition of urban villages in the Chinese peri-urban area. Urban Stud 50(10):1919-1934

Wu FL, Li ZG (2005) Sociospatial differentiation: processes and spaces in subdistricts of Shanghai. Urban Geogr 26(2):137-166

Wu FL, Webber K (2004) The rise of "foreign gated communities" in Beijing: between economic globalization and local institutions. Cities 21(3):203-213

Wu K (2017) Housing reform, life course and urban housing acquisition (1980-2010). Sociol Stud 32(5):64-89

Wu M, Li Z, Xiao Y (2018) Study on spatial-temporal evolution of residential differentiation in Shanghai from an employee perspective. China City Plan Rev 27(3):6-15

Wu QY, Cheng JQ, Chen G et al (2014) Socio-spatial differentiation and residential segregation in the Chinese city based on the 2000 community-level census data: a case study of the inner city of Nanjing. Cities 39:109-119

Wu W (2002) Migrant housing in urban China choices and constraints. Urban Aff Rev 38:90-119 
Xiao Y, Chen S, Wang X et al (2016) Study on segregation of residential space of new migrants in Shanghai from the perspective of global city. City Plan Rev 40(3):25-33

Xu X, Hu H, Yeh C-O (1989) A factoral ecological study of social spatial structure in Guangzhou. Acta Geogr Sin 44(4):385-399

Yang S (2005) Study on the social structure evolvement of megapolis: a case study of Shanghai. Urban Plan Forum 5:17-22

Zhang L (2001) Migration and privatization of space and power in late socialist China. Am Ethnol 28(1):179-205

Zhang L (2010) The right to the entrepreneurial city in reform-era China. China Rev 10(1):129-156

Zhang L, Wang G (2010) Urban citizenship of rural migrants in reform-era China. Citizsh Stud 14(2):145-166

Zhang X, Yang J, Wang S (2011) China has reached the Lewis turning point. China Econ Rev 22(4):542-554

Open Access This chapter is licensed under the terms of the Creative Commons Attribution 4.0 International License (http://creativecommons.org/licenses/by/4.0/), which permits use, sharing, adaptation, distribution and reproduction in any medium or format, as long as you give appropriate credit to the original author(s) and the source, provide a link to the Creative Commons license and indicate if changes were made.

The images or other third party material in this chapter are included in the chapter's Creative Commons license, unless indicated otherwise in a credit line to the material. If material is not included in the chapter's Creative Commons license and your intended use is not permitted by statutory regulation or exceeds the permitted use, you will need to obtain permission directly from the copyright holder. 